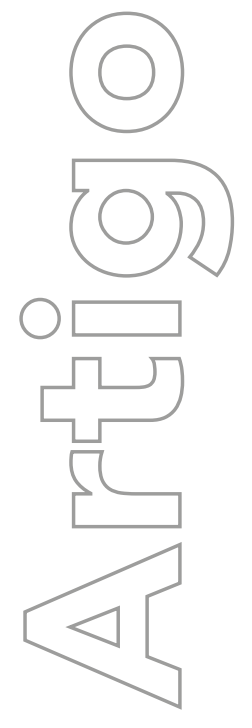

revista

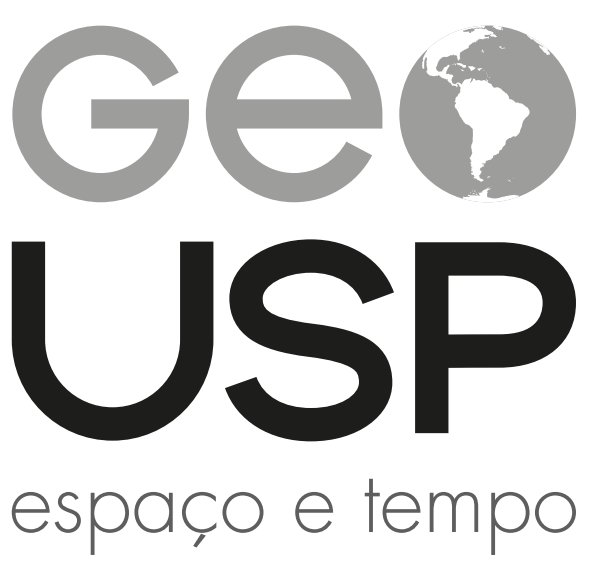

Volume $25 \cdot n^{\circ} 1$ (2021)

ISSN 2179-0892

\section{Notas metodológicas en las postulaciones teóricas de Henri Lefebvre}

\author{
Enrique de Jesús Castro Martínez \\ Universidad Nacional Autónoma de México. \\ Cidade do México. México \\ quiquecasmar88@outlook.es \\ (1) 0000-0001-5347-2085
}

e-166111

Como citar este artigo:

CASTRO MARTíNEZ, E. J. Notas metodológicas en las postulaciones teóricas de Henri Lefebvre. Geousp, v. 25, n. 1, p. 1-19, e-166111, 2021, ISSN 2179-0892.

Disponivel em: https:www.revistas.usp.br/geousp/article/ view/166111/4. doi: https://doi.org/10.11606/issn.2179-0892. geousp.2021.166111.

\section{(c) ${ }_{\mathrm{BY}}$}

Este artigo está licenciado sob a Creative Commons Attribution 4.0 Licence 


\title{
Notas metodológicas en las postulaciones teóricas de Henri Lefebvre ${ }^{1}$
}

\section{Resumen}

El artículo tiene como objetivo proponer que la amplitud teórica de Henri Lefebvre conlleva distintos diseños metodológicos, además del método dialéctico. Para cumplir con lo anterior, se apela a que el pensamiento de Lefebvre se concibe de manera tríadica y su postura epistemológica corresponde a un enfoque heterodoxo que da luz sobre la cuestión del método. A partir de esto, se pone de relieve algunos postulados que respaldan la presente investigación como: el método regresivo-progresivo; los juegos de tríadas se pueden relacionar promoviendo un diseño metodológico de totalidades abiertas; y, la teoría unitaria de la producción del espacio que fragmentada por dimensiones espaciales responden a configurar un método de análisis teórico-conceptual, aunque dejando diversas posibilidades al usuario del punto de aplicación que serviría como sustento teórico-metodológico en las proposiciones en David Harvey, Edward Soja y Neil Brenner.

Palabras clave: Henri Lefebvre. Método. Teoría. Tríadas. Heterodoxo.

\section{Methodological notes in the theoretical postulations of Henri Lefebvre}

\begin{abstract}
The article aims to propose that the theoretical breadth of Henri Lefebvre entails different methodological designs, in addition to the dialectical method. In order to accomplish the above, it is appealed that the thought of Lefebvre is conceived in a triadic way and his epistemological posture corresponds to a heterodox aproach that gives light on the question of the method. From this, it highlights some postulates that support the present research as: the
\end{abstract}

Agradezco al Programa de Apoyos a la Investigación e Innovación Tecnológica. PAPIIT IN302120. "Financiarización del mercado inmobiliario: nuevas formas, actores y escalas en la producción del entorno construido en la ciudad contemporánea". 
regressive-progressive method; triad games can be related by promoting a methodological design of open totalities; and, the unitary theory of the production of space that fragmented down by spatial dimensions respond to configure a theoretical-analysys methodconceptual, although leaving various possibilities to the user of the point of application that would serve as theoretical-methodological support in the propositions in David Harvey, Edward Soja and Neil Brenner.

Keywords: Henri Lefebvre. Method. Theory. Triads. Heterodox.

\section{Notas metodológicas sobre as postulações teóricas de Henri Lefebvre}

\section{Resumo}

$\bigcirc$ artigo tem como objetivo propor que a amplitude teórica de Henri Lefebvre implica diferentes desenhos metodológicos, além do método dialético. Para cumprir com o anterior, apela-se a que o pensamento de Lefebvre seja concebido de forma tríplice e sua postura epistemológica corresponde a uma abordagem heterodoxo que dá luz sobre a questão do método. A partir disto, destaca-se alguns postulados que apoiam a presente pesquisa como: o método regressivoprogressivo; os jogos de Tríades podem se relacionar promovendo um desenho metodológico de totalidades abertas; e, a teoria unitária da produção do espaço que fragmentada por dimensões espaciais respondem a configurar um método de análise teórico-conceitual, embora deixando diversas possibilidades ao usuário do ponto de aplicação que serviria como sustento teórico-metodológico nas proposições em David Harvey, Edward Soja e Neil Brenner.

Palavras-chave: Henri Lefebvre. Método. Teoria. Tríades. Heterodoxo.

\section{Introducción}

Hoy en día estamos experimentado una urbanización a escala global revindicando el pronóstico de Henri Lefebvre que señalaría en los albores de 1970. Esto ha potencializado grandes metamorfosis en las metrópolis contemporáneas generando que los anteriores planteamientos teóricos tiendan hacer fortalecidos para analizar la nueva cuestión urbana que aqueja en nuestro planeta. Por esto, en diversas latitudes se ha reivindicado las aportaciones teóricas de Lefebvre en los estudios urbanos. 
Bajo estas especificidades es posible que el lector al momento de consultar la obra literaria de Lefebvre haya pasado desapercibido y que de manera involuntaria este implementando algún tipo de diseño metodológico. Es importante mencionar que el pensamiento dialéctico de Lefebvre contribuya a potencializar los distintos diseños metodológicos. Por tal motivo, proponemos el siguiente sustento teórico que respalda la existencia de otros métodos que han definido el pensamiento Lefebvriano. Para avalar la evocación anterior, Lefebvre (1976a, p. 224) escribe lo siguiente: "soy partidario de una especie de pluralismo metodológico; hay que conseguir la convergencia" y las contradicciones.

A esta unión de postulados abiertos, pero a la vez posibles, se apela a una serie de apologías que son imprescindibles para descifrar los métodos de Lefebvre, por ello, sugerimos las siguientes proposiciones: en primera instancia corresponde al enfoque heterodoxo y triádico de la realidad; segundo responde a la relación de posibles juegos de tríadas dando alternativas metodológicas para la exegesis de la espacialidad para evitar la reducción y fragmentación del conocimiento en sus diferentes aristas.

Para lograr lo anterior, el posterior documento se sitúa en cinco apartados. El primero responde en analizar la conceptualización del método en términos de Henri Lefebvre; segundo es mencionar que la concepción del pensamiento de Lefebvre corresponde a cuestiones triples; el tercer momento se analiza el método regresivo-progresivo; cuarto se sitúa la teoría unitaria de la producción de espacio como un diseño metodológico; y, por último, es la influencia teórica- metodológica de Lefebvre en el pensamiento de Neil Brenner, Edward Soja y David Harvey.

\section{El método en la concepción de Henri Lefebvre}

A lo largo de los escritos de la obra de Henri Lefebvre, el lector es sumergido a marcos históricos y teóricos que definen sus proposiciones conceptuales, en algunos casos aparecen algunas ideas metodológicas para sustraer la raíz teórica con base a su enfoque heterodoxo y pensamiento terceto con la intención de promover nuevos postulados alternativos ante el dominio dogmático y las múltiples modalidades reduccionistas (Lefebvre, 1975, p. 63-65).

Por ejemplo, para extraer el pensamiento crítico de los textos clásicos, Lefebvre y Guterman (1964, p. 13) escriben que hay dos métodos tradicionales y opuestos: por un lado, el método meramente interno que "[...] conduce al desarme de la crítica y a la desvirilización del pensamiento. Corresponde al liberalismo invertebrado que confronta y que discute sin cesar", por el otro lado, el método externo que tiene que ver con "el del moralista que juzga, del dogmático cortante $[\ldots .$. " y de frecuencia reiterativa.

Una de las postulaciones metodológicas que resuenan en los escritos de Lefebvre es la cuestión de la transducción, que: "es una operación intelectual que puede proseguirse metódicamente y que difiere de la inducción y la deducción clásicas, así como de la construcción de modelos, de la simulación, del simple enunciado de hipótesis" (Lefebvre, 1978, p. 128) que: "[...] permite construir objetos virtuales, en un incesante ir y venir entre lo real y lo posible. En este caso, hay construcción" (Lefebvre, 1976b, p. 65) teórica. 
Otras notas metodológicas que emergen en los escritos de Lefebvre es el análisis del fenómeno urbano, que, según él, comprende a tres métodos descriptivos, el primero utiliza como sustento analítico a la ecología; el segundo es la descripción fenomenológica; y, el tercero responde a la descripción empírica de la sociedad en correlación a los cambios morfológicos que se dan en la ciudad (Lefebvre, 1976c, p. 54), aunque la utilización de dichos métodos, como advierte Lefebvre (1976a, p. 228): "[...] la descripción, aun rigurosa y afinada, no basta", p. 228), mientras que para estudiar El Capital es importante promover un diseño metodológico y de sustento teórico mediante la relación de tres conceptos que son: forma, función y estructura (Lefebvre, 1976d, p. 22) y, para analizar el habitar se emplean técnicas y métodos como son las entrevistas no dirigidas, datos sensibles y datos reproducidos (Lefebvre, 1976a, p. 160-161).

El andamiaje es amplio de las postulaciones metodológicas en la obra literaria en Lefebvre, algunas son citadas, pero son deconstruidas y reconstruidas para proponer otro término que en ocasiones suele ser con orientación triple y en otros postulados es complicado diseñar el armazón teórico para después sustraer el sustento metodológico. ${ }^{2}$

Ante estas propuestas que emergen en la lectura de Lefebvre, en las últimas décadas ha tomado mayor resonancia la incógnita que comprende a la siguiente pregunta: ¿las aportaciones teóricas de Henri Lefebvre pueden ser consideradas como diseños metodológicos? Algunos expertos que se han dedicado a los estudios de la obra literaria de Lefebvre han respondido al anterior planteamiento. Por ejemplo, Remi Hess uno de los principales exponentes considerado como el bibliógrafo de Lefebvre apunta lo ulterior con respecto al método: "[... no hizo ningún trabajo metodológico. No hizo específicamente enseñanza metodológica" (Hess, 2004, traducción nuestra) y, en años posteriores Stanek y Schmid (2011) nombraría a uno de sus artículos con un título sugestivo: "Teoría, no método: Henri Lefebvre, investigación y diseños urbanos en la actualidad".

De lo anterior, por un lado, coincidimos con las afirmaciones de Hess, Stanek y Schmid que Lefebvre no propuso metodologías formales asociadas con investigaciones de corte científico, en particular, las que derivan de las ciencias exactas, ${ }^{3}$ pero, por el otro lado, consideramos que algunas de sus propuestas pueden ser consideradas como diseños metodológicos en cuanto su aplicación de análisis teórico, aunque no de manera tradicional donde se guie al usuario por incisos como lo es el método racionalista o empírico-analítico que prevalecen conjuntos de pasos a seguir. ${ }^{4}$ Por ello, Henri Lefebvre (1976b, p. 63, traducción nuestra) apunta lo siguiente con base a la formulación del método:

La parte del método (objeto de una disciplina particular llamada metodología) y su papel en las ciencias sociales no carecen de ambigüedad. Las consideraciones

2 Por ejemplo, la práctica poética (Lefebvre, 2018, p. 90).

3 En estos los métodos de las ciencias denominadas exactas, se reconocen como esenciales los problemas de terminología. La nomenclatura prepara los conceptos y los resúmenes (Lefebvre, 1967, p. 11). Aunque, la clasificación no basta: la nomenclatura, necesaria, remite a otra cosa: el proceso del conocimiento y el de la realidad. Por consiguiente, hay una consigna metodológica: restituir y situar (restituir situando, situar restituyendo) (Lefebvre, 1967, p. 139).

4 Para ampliar la discusión, véase a Lefebvre (1973a, p. 150-151, 1976a, p. 117, 1980). 
metodológicas juegan un papel importante, formalizado en los géneros académicos: tesis, investigación, trabajo del programa. El trabajo comienza regularmente con la metodología, refugio del conocimiento, ¿reemplaza y suplanta el conocimiento? Tiene el apoyo, por supuesto, de la epistemología, que solo quiere ser verdadero, aún cierto, certificado por el método.

A esto, "ningún método asegura una cientificidad absoluta, teórica o práctica" (Lefebvre, 1976c, p. 73) ningún modelo matemático o leyes universales puede explicar los distintos espacios diferenciales, a esto queda que el conocimiento crítico no se sustrae como resultado de metodologías científicas, sino que la teoría delinea al método, es decir, "el método no puede separarse de la teoría. Toma forma con la teoría" (Lefebvre, 1976b, p. 64), por ejemplo: la teoría unitaria de la producción del espacio que no involucra un método formalizado por la cientificidad, ya que es una posible metodología que involucra relaciones posibles en cuanto su análisis por dimensiones espaciales.

Así, "el método consiste en reunir para situar; acerca lo que separa y, por el contrario, separa lo que se acerca exageradamente y discierne aquello que tiende a la confusión" (Lefebvre, 1975, p. 129). A esto mismo, podemos mencionar que el método involucra relaciones posibles, con capacidades movibles, pero en constantes antagonismos (Lefebvre, 1973b, p. 29; 1974a, p. 17) de carácter triple.

El método bajo el sustento teórico de Henri Lefebvre se relaciona con el concepto de la totalidad, para ello Lefebvre y Guterman (1964, p. 37) mencionan que la "[...] totalidad como un círculo, como una esfera, como cerrada" mientras que "[...] la totalidad abierta puede envolver otras totalidades igualmente abiertas, pudiéndose implicarse a profundidad [...]" (Lefebvre, 2011, p. 105), a propósito, el propio "pensamiento, considerado en su conjunto y en su movimiento, es otro ejemplo de totalidad abierta" (Lefebvre; Guterman, 1964, p. 38).

Adicionalmente, Lencioni (2015, p. 61) menciona que un punto importante de la totalidad abierta tiene que ver con "[...] la causa y efecto son momentos de interdependencia universal y únicamente la perspectiva de análisis que concibe la totalidad como abierta y en movimiento puede comprenderlas en su dimensión de condicionantes, sin tomarlas de modo absoluto o completo", aunque, otra particularidad del pensamiento de Lefebvre corresponde al concepto de los momentos. A esto, Theodore, Peck y Brenner (2009, p. 7) escriben que el uso de este término comprende "[...] al sentido hegeliano-marxista de elementos en conflicto, pero mutuamente relacionados al interior de un proceso dinámico, dialéctico, más que a una descripción de unidades temporales distintas en una transición lineal".

Por tal motivo, el pensamiento de Lefebvre responde a totalidades abiertas con concepciones triádicas, en "ella se determina como esfera de esferas, totalidad infinita de totalidades cambiantes, parciales, implicándose recíprocamente a profundidad, en y por los conflictos mismos" (Lefebvre, 2011, p. 121). Por ejemplo, para analizar la urbanización planetaria se debería de partir desde la teoría unitaria de la producción del espacio retomando los momentos del método regresivo-progresivo para descifrar la expansión a escala mundial que ha imbricado desde el suelo, subsuelo y el sobre suelo de las metrópolis (Gráfica 1). 


\section{Gráfica 1 - Posibles totalidades abiertas en el pensamiento triádico de Henri Lefebvre: producción del espacio del capital}

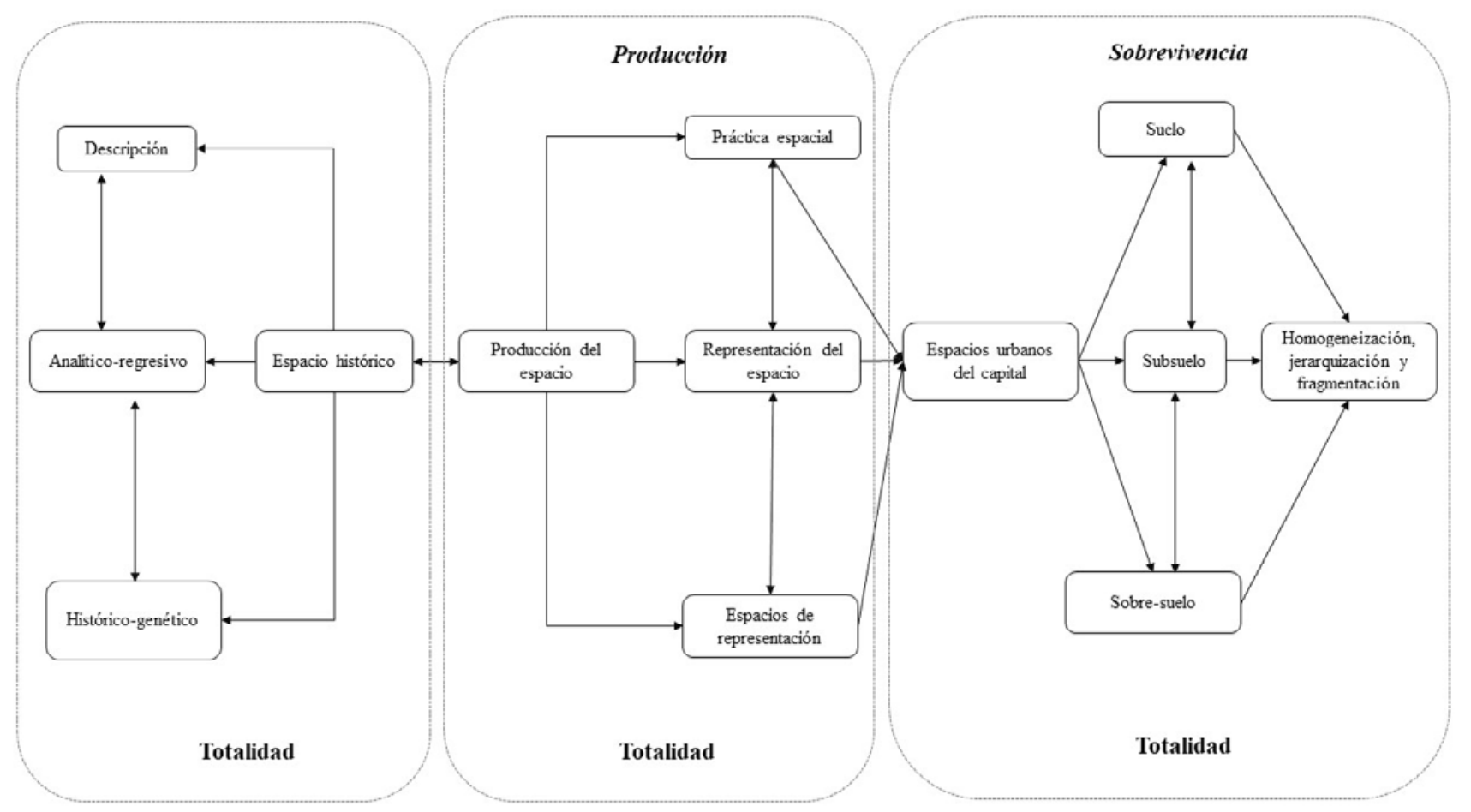

fuente: Elaboración propia a partir de Lefebvre (1976a, 2013).

Cada una de las postulaciones triples se encuentran relacionadas pero en constantes antagonismo, son totalidades abiertas en la producción del espacio del capital, aunque no responden a configurar leyes y categorías que puedan reproducirse como característica principal del método científico, sino que: "tanto en la ciudad de ayer como en la del futuro, no existe el espacio urbano, sino espacios urbanos, varios espacios diferenciados [...]" (Lefebvre, 1976a, p. 211) que responden a ciertas prácticas y lógicas del capital.

\section{E1 pensamiento tríadico como método}

El enfoque heterodoxo de Henri Lefebvre contiene momentos particularidades para comprender la concepción de la realidad, uno de ellos tiene que ver con el pensamiento orientado a la totalidad por medio de planteamientos tercetos, en contra de los planteamientos con enfoque único o binario, ante esta problemática Lefebvre (2006, p. 176) argumenta lo siguiente:

El pensamiento reflexivo, por lo tanto, filosófico insistió durante mucho tiempo en las díadas. Las de lo seco y lo húmedo, de lo grande y de lo pequeño, del orden y del desorden, de lo finito y lo infinito, en la antigüedad griega. Luego las que constituyen el paradigma filosófico de Occidente: sujeto-objeto, continuo-discontinuo, abierto-cerrado, etc. Por último, en la época moderna las oposiciones binarias del significante y del significado, del saber y no saber, del centro y de la periferia, etc. Ahora bien, una estructura triádica presente desde hace mucho tiempo en el logos occidental emerge desde Hegel. 
Sin embargo, no podemos considerar que todo el pensamiento ha sido a través de tríadas en las postulaciones en Lefebvre, en ocasiones surgen planteamientos binarios como es el proceso de implosión-explosión que aparece en el libro de La revolución urbana (1976c). Sin embargo, es considerable la amplitud de propuestas con orientación triádica en los textos de Lefebvre, a guisa de ejemplo, de este diseño particular de tres en tres, "siempre somos tres. Siempre hay el otro [como] [...] las del espacio, la música (melodía, armonía, ritmo), las del lenguaje (sintagma, paradigma, simbolismo) [...]" (Lefebvre, 2006, p. 176), los tres enfoques de la planificación urbana en asociación con el Estado y la Economía (el balance material, el balance financiero y la planificación espacial) (Lefebvre, 1977, p. 222-223) y las categorías fundamentales de la filosofía que comprenden a "[...] la totalidad (globalidad), la negatividad (crítica y dialéctica), la posibilidad (lo virtual, lo utópico, utopiano)" (Lefebvre, 2006, p. 117, énfasis del original).

A este planteamiento triple, Lefebvre (1967, p. 166) se formula algunas críticas que podría recibir, él escribe los siguientes cuestionamientos:

Algunos lectores no dejarán de objetar: "Usted pretende liberarse de las categorías hegelianas: tesis, antítesis, síntesis, o de las categorías de una dialéctica fija: afirmación, negación, negación de la negación". Pero lo mismo que Hegel y los dialécticos que lo siguieron, exhibe una manía respecto del número tres. ¿De quién ha heredado ese fetichismo? ¿De los arios estudiados por el estructuralismo de Georges Dumézil? ¿De los romanos y los griegos? ¿O de la tradición cristiana? ¡Se equivoca si cree que puede superar a la filosofía y la teología!

Aunque de la evocación anterior establece la importancia de los planteamientos triádicos y abre la posibilidad de rastrear la formación del pensamiento triple, se suma otra de las incógnitas que ha surgido en la actualidad que responde a la posibilidad de relacionar juegos de tríadas, Lefebvre (2006, p. 177) realiza un ejercicio donde propone asociaciones de tercetos, pero dejando posibles comienzos de aplicación. Ahora bien, una alternativa sería partiendo desde la práctica del capital como proceso de producción del espacio, pero antes se tiene que conocer la historia del espacio por el método regresivo progresivo que permite desgranar la teoría unitaria de las producción del espacio (Lefebvre, 2013, p. 72) con la intención de descifrar la función del capital financiero-inmobiliario que ha potencializado cambios en la estructura urbana como son los subcentros urbanos o "las redes de centros comerciales" (Lefebvre, 1976e, p. 55) ampliando sus formas constructivas promoviendo a jerarquizar, fragmentar y homogenizar a las ciudades a escala mundial.

A esto mismo, coincidimos con Lencioni (2015, p. 58) al mencionar que Lefebvre "[...] orientó metodológicamente sus análisis al constituir un parámetro para concebir una forma de pensar basada en tríadas, las cuales permiten componer un universo de infinitas totalidades" que responde a un "análisis que se ha convertido en dialéctico, de esta manera se preocupa de tres términos" (Lefebvre, 2007, p. 12) y, que algunos han denominado como la "dialéctica tridimensional" (Schmid, 2008, p. 33) o "dialéctica de triplicidad" (Soja, 2010, p. 193). 


\section{El método regresivo-progresivo en Lefebvre}

Durante mucho tiempo se ha afirmado que el método regresivo-progresivo de Lefebvre es una propuesta del método dialéctico de Marx (Martins, 1996, 2011; Hess, 2004; Elden; Morton, 2015), el propio Lefebvre (1976f, p. 144) da cuenta de esto a dilucidar la aplicación teórica que realizaría Sartre: "sucede, no obstante, que el método en cuestión no es otro que el de Marx, explicitado en mi célebre texto, lo que ha embrollado curiosamente este problema teórico resuelto torpemente por Sartre". Aunque coincidimos que el método tenga similitudes, ${ }^{5}$ debido a la influencia que adquirió de Marx, ${ }^{6}$ pero también distinciones debido al pensamiento heterodoxo y triple de Henri Lefebvre.

A esto, nos enfocamos a generar algunas ideas que componen al método regresivo-progresivo para dar elementos de un sustento teórico. Así pues, el método regresivo-progresivo lo exponemos mediante dos momentos que son complementarios: el primero atañe al marco teórico de Lefebvre y, el segundo responde a las observaciones empíricas que servirían como sustento teórico del anterior momento. Pero antes, un tema central que Lukasz Stanek (2008, p. 223-224) señala sobre la construcción del método-regresivo es la influencia que adquirió de la tradición de los historiadores franceses de los finales del siglo XIX y principios de XX, en particular con las aportaciones de Marc Bloch sobre la historia rural de Francia.

Retomando los momentos que proponemos, el primero se sitúa en una de sus preocupaciones de la reducción y fragmentación del conocimiento que en tiempos atrás y actuales se ha confirmado y reafirmando la carencia de marcos teóricos e históricos. Por ello, su propia investigación, es decir: "[...] el movimiento del conocimiento, parte de lo actual para remontarse al pasado. El método es regresivo antes de ser presente. La reflexión esclarece la historia a partir del presente" (Lefebvre, 1973a, p. 17) Algunos ejemplos de la idea anterior es el surgimiento del concepto de lo urbano (Hess, 2004), la revisión teórica del Estado para proponer después el modo de producción estatal (Lefebvre, 1976b, p. 63-96; 1977, p. 189-251), la representación (Lefebvre, 2006, p. 21-112), la diferencia e in-diferencia (Lefebvre, 1975), la modernidad (Lefebvre, 1971, p. 155-214) entre otras más.

En segundo momento explicativo no puede separarse del anterior, se relacionan en Lefebvre para dar cuenta de la concretización del sustento teórico con base a ejemplos empíricos que observaría Lefebvre, una de ellas sería la metamorfosis de la sociedad burocrática del consumo dirigido, a esto mismo se tiene que regresar para analizar la sociedad industrial, sociedad tecnocrática-burocrática, sociedad de abundancia, sociedad del ocio y la sociedad de consumo (Lefebvre, 1984, p. 62-79).

$\bigcirc$ bien, las transformaciones que sucedían en los pirineos ubicados en Francia por la urbanización planetaria que tomaría mayor resonancia por el proceso de industrialización que desplazaría a lo rural. En respuesta a estas transiciones donde lo urbano que ha tomado un

5 Para conocer más sobre las posibles similitudes del método, véase a Henri Lefebvre (1973c, p. 29, 1974a, p. 17, 1976d, p. 13).

6 Una aclaración central es la formación del método en Marx, a este propósito se cita siempre el célebre párrafo del Prefacio a El Capital: Mi método dialéctico no difiere sólo por sus fundamentos del método hegeliano, sino que es directamente lo contrario... En Hegel, se mantiene sobre la cabeza; es necesario ponerlo sobre sus pies para descubrir el núcleo racional bajo la envoltura mística... (Lefebvre, 1965, p. 58), otro esclarecimiento referente al método es distinguir entre el método de investigación y el método de exposición (Lefebvre, 1973a, p. 155-179, 1974b, p. 83-106, 1976g, p. 78-84). 
ascenso importante, Lefebvre (1976b, p. 64-65, traducción nuestra) lo estudiaría a través del método regresivo-progresivo. Al respecto, menciona la siguiente afirmación:

El pasado no ilumina y no explica el presente mediante una secuencia causal.

El futuro no comprende el presente y el pasado por finalismo (una teleología, siempre algo teológico). Lo hace posible captar la corriente y los antecedentes, precisamente porque sale de ella y que lo posible es parte de lo real, considera dinámicamente. Por lo tanto, los consecuentes exponen lo que contenían los anteriores, con la condición de seguir el proceso de que uno puede decir genético si se observa el movimiento global, o genealógico si se presta atención a los nacimientos de lo que sucede.

Un tema central de la evocación anterior responde a la cuestión de la escala que relaciona al método regresivo-progresivo, al respecto: "el análisis debe situarse, o intentar ubicarse, a nivel planetario [que configurará una] [...] multiplicidad de escalas y niveles, por lo tanto, una morfología jerárquica estratificada (donde lo macro implica los niveles micro y los niveles intermedios) [...]" (Lefebvre, 1976b, p. 67). Es decir, la génesis se parte de lo planetario para situarse a lo genealógico que responde a lo local.

En las citas anteriores se ha observado que el método regresivo-progresivo se sustenta por dos momentos, aunque la concepción del conocimiento en Lefebvre no se formule a través de planteamientos binarios, sino que es un pensamiento tríadico (Schmid, 2008, p. 28; Lencioni, 2015, p. 64).

El planteamiento terceto del método regresivo-progresivo "[...] está expuesto en dos artículos de Lefebvre publicados en Cahier Internationaux de Sociologie, en 1949 y 1953" (Martins, 1996, p. 20), a esta última publicación hace referencia al escrito "Perspectivas de la sociología rural" publicado en el libro titulado De lo rural a lo urbano (Lefebvre, 1976a). En dicho texto es una crítica a los métodos que adoptan distintos campos disciplinarios para el análisis del espacio mediante la realidad horizontal y vertical, ${ }^{7}$ como aquellos que hacen uso de la lógica formalizada para el estudio del espacio por medio de estadísticas, clasificaciones o la generación de tratados monográficos.

En respuesta a estas problemáticas metodológicas, Lefebvre (1976a, p. 71) propone los siguientes momentos y técnicas auxiliares que comprenden al método regresivo-progresivo:

a. Descripción. Observación, pero informada por la experiencia y una teoría general. En primer plano: la observación sobre el terreno. Utilización prudente de las técnicas de encuestas (entrevistas, cuestionarios, estadísticas).

b. Analítico-regresivo. Análisis de la realidad escrita. Intento de fecharla exactamente (para no contentarse con una relación de "arcaísmos" sin fecha, sin comparación unos con otros).

7 Para conocer sobre el tema, véase a Lefebvre (1976a, p. 63-64). 
c. Histórico-genético. Estudio de las modificaciones aportadas a la estructura en cuestión, una vez fechada, por el desarrollo ulterior (interno o externo) y por subordinación a estructuras de conjunto. Intento de una clasificación genética de las formaciones y estructuras, en el marco del proceso de conjunto. Intento, por tanto, de regresar a lo actual precedentemente descrito, para reencontrar lo presente, pero elucidado y comprendido: explicado.

De las ideas antes expuestas, José de Souza Martins (1996, p. 21, traducción nuestra) apunta lo siguiente a los dos primeros momentos del método regresivo-progresivo:

La complejidad horizontal de la vida social puede y debe reconocerse en la descripción de lo visible. Depende del investigador reconstruir, desde una mirada teóricamente informada, la diversidad de las relaciones sociales, identificando y describiendo lo que ve. Este es el momento descriptivo del método. En él, el tiempo de cada relación social aún no está identificado. El investigador procede más como etnógrafo. El segundo momento es regresivo-analítico. A través de él nos sumergimos en la complejidad vertical de la vida social, la de la coexistencia de relaciones sociales que tiene fechas desiguales. En ella se analiza la realidad, se descompone. Esto es cuando el investigador debe hacer un esfuerzo para fecharlo exactamente. Cada relación social tiene su edad y fecha. Cada elemento de la cultura material y espiritual también tiene su fecha. Lo que al principio parecía simultáneo y contemporáneo ahora se descubre como un remanente de una era específica.

Y para el último momento del método Martins (1996, p. 22, traducción nuestra) menciona:

El tercer momento del método dialéctico de Lefebvre es histórico-genético. En ella, el investigador debe buscar el reencuentro del presente, "pero aclarado, entendido, explicado". El retorno a la superficie fenoménica de la realidad social aclara lo percibido por lo concebido teóricamente y define las condiciones y posibilidades de lo vivido. En este momento regresivo-progresivo es posible descubrir que las contradicciones sociales son históricas y no se reducen a confrontaciones de intereses entre diferentes categorías sociales. Por el contrario, en la concepción Lefebvriana de contradicción, los desajustes son también desajustes de tiempos y, por lo tanto, de posibilidades.

Es importante mencionar la doble interpretación que se sustrae del último momento regresivo-progresivo, por un lado, lo vivido como espacio de resistencia que diseñaría lo percibido y lo concebido de un individuo, pero, por otro lado, lo social como producción de espacio mediante las prácticas de la lógica de capital en asociación con la representación instrumental del espacio bajo el dominio y el control de las múltiples interpretaciones de los espacios de representación. 
Un punto relevante que concierne al último momento del método bajo custodia es la capacidad de impulsar la resistencia que deriva del contra espacio ante las lógicas de las practicas materiales del capital, en este sentido, Martins (2011, p. 4) da cuenta de esto mismo añadiendo que "el método regresivo progresivo se refiere a la premisa de la totalidad abierta e inconclusa, en la que las superaciones propone nuevas contradicciones y nuevas tensiones, la sociedad moviéndose y transformándose todo el tiempo".

\section{La teoría unitaria de la producción del espacio como diseño metodológico}

Una de las problemáticas que formula Henri Lefebvre (2013, p. 68) reviste el interés central por la fragmentación y reducción del conocimiento, al respecto, apunta lo siguiente:

Las investigaciones acaban en meras descripciones, que en ningún momento llegan a alcanzar el estatus analítico mucho menos el teórico, o terminan en fragmentos y secciones del espacio. Hay muchas razones que inducen a pensar que esas descripciones y esos recortes tan solo aportan inventarios de lo que existe en el espacio, o en el mejor de los casos dan lugar a un discurso sobre el espacio, pero nunca a un conocimiento del espacio.

El interés era de generar una teoría donde se relaciona las concepciones de la realidad sustraída de la razón mental, la cuestión física y lo social en respuesta de la reducción y desintegración del conocimiento vinculado al método científico, por lo cual, desarrollaría una propuesta que engloba tres dimensiones que comprenden:

En primer lugar, del fisico, la naturaleza, el Cosmos; a continuación, del mental (incluida la abstracción formal y la lógica); y, por último, del social. En otros términos, la investigación concierne al espacio lógico-epistemológico, al espacio de la práctica social, al espacio ocupado por los fenómenos sensibles, sin excluir lo imaginario, los proyectos y proyecciones, los símbolos y las utopías (Lefebvre, 2013, p. 72).

Del planteamiento anterior podemos extraer tres ideas claves que relaciona a la teoría unitaria de la producción del espacio: el primero responde a lo mental que después denominaría como representación del espacio que está constituido por la razón instrumental del saber científico donde predomina la cuestión geométrica del espacio por el predominio de métodos formales; segundo tiene que ver con las relaciones sociales de producción y reproducción; y, tercero lo que denomina como la cuestión física o naturaleza que comprende a las dimensiones simbolizadas que el ser humano tiene la capacidad de imaginar y de percibir. A continuación, mencionamos cada una de las dimensiones espaciales.

\section{Práctica espacial}

Como lo señalaría Lefebvre al mencionar que: "hoy en día pocos rehusarían admitir la influencia de los capitales y del capitalismo en las cuestiones prácticas relativas al 
espacio, desde la construcción de inmuebles a la distribución de inversiones y a la división mundial del trabajo" (Lefebvre, 2013, p. 70), al unisonó, reviste el interés central de las prácticas y sus lógicas del capital que son espacialiazadas en la producción en el espacio pero de manera simultánea a la producción del espacio donde intervienen diversos actores en su reproducción.

En esta dinámica que propicia la lógica del capital, puede resumirse de la siguiente manera: "la práctica espacial, que engloba producción y reproducción, lugares específicos y conjuntos espaciales propios de cada formación social; práctica que asegura la continuidad en el seno de una relativa cohesión" (Lefebvre, 2013, p. 92), ya que toda "[...] sociedad secreta su espacio; lo postula y lo supone en una interacción dialéctica; lo produce lenta y serenamente dominándolo y apropiándose de él" (Lefebvre, 2013, p. 97).

La configuración del espacio desde la práctica del capital involucra a las fuerzas productivas (naturaleza, trabajo y organización del trabajo) y las relaciones sociales de producción. Además, que el espacio es "producto que se utiliza, que se consume, es también medio de producción: redes de cambio, flujos de materia prima y de energías que configuran el espacio y que son determinados por él" (Lefebvre, 2013, p. 141) para ser "[...] consumido productivamente [...]" (Lefebvre, 2013, p. 382) al interior y al exterior del propio espacio. Así pues, las prácticas de las relaciones sociales y las fuerzas productivas auspician la producción del espacio como medio y producto del capital, es decir, el espacio mismo forma parte de la lógica del capital, desde su producción hasta su reproducción, en donde "[...] la práctica espacial en su totalidad lo que ha permitido la supervivencia del capitalismo" (Lefebvre, 2013, p. 379).

\section{Representación del espacio}

La siguiente dimensión espacial conlleva dos interpretaciones que se relacionan para su configuración, la primera responde a considerar al espacio mental mediante la lógica formalizada e instrumental que deriva del método científico, a esto Lefebvre (2006, p. 151) escribe que "[René] Descartes construyó el marco general del Logos europeo, las principales representaciones de la naturaleza y de la sociedad: el espacio mental y la eficacia, el orden y la medida, la cuantificación, la lógica matemática".

En esta misma línea se sitúa el pensamiento de los filósofos: Spinoza, Kant, Leibniz, los newtonianos y el espacio kantiano, relativo, instrumento de conocimiento, medio de clasificación de los fenómenos (Lefebvre, 2013, p. 63) que después la lógica-matemática denominaría con distintos términos alusivos como: "[...] espacios no-euclidianos, espacios curvos, espacios $\mathrm{x}$-dimensionales, (e incluso una infinidad de dimensiones), espacios de configuración, espacios abstractos [...]" (Lefebvre, 2013, p. 64).

En la segunda comprende a la representación del espacio bajo la conceptualización de la forma del Estado, en donde uno de los máximos exponentes que ha configurado la concepción de esta dimensión espacial es Hegel como teórico del Estado. A lo largo de la historia el Estado ha tenido grandes transformaciones, en pleno siglo XX, dice Lefebvre (2013, p. 83): "el Estado se consolida a escala mundial", que se sitúa durante el modelo económico keynesiano-fordista donde "el Estado moderno a escala mundial. Recae plenamente sobre la sociedad" que "[...] ya 
no es hegeliano en el sentido de que hay reparto de poder" (Lefebvre, 1976h, p. 111) y esos poderes "[...] la planifica, la organiza racionalmente con la contribución de conocimientos y técnicas, imponiendo medidas análogas si no homogéneas, cualesquiera que sean las ideologías políticas [...]" (Lefebvre, 2013, p. 83).

Ya que "prueba de ello es que en los países de todo tipo alrededor de los años de 1960 se comenzó a hablar del milagro: el milagro alemán, francés, japonés y también del milagro español" (Lefebvre, 2012, p. 141). A este tipo de Estado moderno lo denominaría: "Modo de Producción Estatal (MPE)" (Lefebvre, 1977, p. 189) que responde a un "[...] Estado gerente, organizado e incluso produciendo el espacio, completando su obra" (Lefebvre, 1976f, p. 216).

Ahora bien, la conceptualización que postula bajo la rúbrica de la representación del espacio en el libro La producción del espacio se inscribe en esta temporalidad, por ello, Lefebvre (2013, p. 97) escribe lo siguiente que el espacio concebido responde a "[...] los científicos, planificadores, urbanistas, tecnócratas, ingenieros sociales y hasta el cierto tipo de artistas próximos a la cientificidad [...]".

\section{Espacio de representación}

Los espacios de representación conllevan matices con una amplitud de tonalidades. Por tal motivo, consideramos tres explicaciones que versan sobre la cuestión del símbolo. Primero se sitúa lo que denomina el espacio de la naturaleza (Lefebvre, 2013, p. 69) que responde a los elementos naturales como es el agua, fuego, aire y la tierra. Es decir, que lo "[... ] simbólico tiene generalmente una relación con lo mágico. Un objeto tomado como símbolo de una realidad inaccesible (lejana o trascendental) posee los amplio supuestos de esta realidad" (Lefebvre, 2018, p. 197).

La segunda explicación tiene que ver con el ascenso de la modernidad promoviendo la alienación del capital a la vida cotidiana, donde la cuestión del símbolo no es ajena a esta problemática. A esto mismo, Lefebvre (1984, p. 53) propone una periodización en tres momentos, la primera se sitúa en "el ascenso de las masas (que no impide su explotación), la democracia (idéntica observación), significan el fin de los grandes estilos, de los símbolos y de los mitos, de las obras colectivas: monumentos y fiestas" y de los primeros símbolos que representan a la naturaleza. El segundo momento se enmarca bajo el periodo de posguerras donde el Estado tuvo una fuerte intervención que prevaleció durante el modelo de desarrollo industrial que impulsaría a la par el proceso de urbanización. El dominio que se promovió fue por la tecnocracia en la planeación de las ciudades que respondía a una cuestión indicativa o racional que se expandió a lo cotidiano de la sociedad. Los espacios de representación no fueron inmunes ante esta concentración y expansión de la técnica en lo cotidiano por el ascenso del capital. El tercer momento y el último es la fase superior de la sociedad burocrática de consumo dirigido que deriva de la alineación de las nuevas tecnologías y medios de comunicación, que generan la "cibernetización" (Lefebvre, 1984, p. 84) o "cotidianidad programada" (Lefebvre, 1984, p. 85) donde el ser humano se volvería dependiente de la era del cibernantropo y del robot (Lefebvre, 1972, p. 165-175).

En la tercera explicación corresponde al contra espacio por el dominio y apropiación de símbolos que promueve la lógica del capital que ha imperado en las grandes ciudades. 
En donde los más desfavorecidos recienten la destrucción de los espacios de representación promoviendo la resistencia que impulsaría las prácticas y las representaciones del espacio para el bien común. Así pues, y "en realidad, para cambiar la vida es preciso cambiar el espacio" (Lefebvre, 2013, p. 236) a través de espacios alternativos que puedan potencializar "[...] contra-planes y contra-proyectos que frustren las estrategias, los planes y los programas impuestos desde arriba" (Lefebvre, 2013, p. 414) como un mecanismo de contra-espacio (Lefebvre, 2013, p. 415) que daría paso a la "[...] revolución del espacio (que incluye, pues, la revolución urbana) [...]" (Lefebvre, 2013, p. 448).

Por último, la teoría unitaria de la producción del espacio que desgranada por dimensiones espaciales permite obtener un diseño teórico-metodológico, pero dejando tres posibles modalidades de aplicación, ya que algunos podrían partir desde la práctica espacial explicando la lógica del capital, en otros desde la representación del espacio en las distintas formas del Estado, o bien, los espacios de representación con sus múltiples interpretaciones.

Un caso relevante comprende a la Geografía Urbana que ha tomado un papel protagónico en la interpretación de las postulaciones de Henri Lefebvre. Una de ellas corresponde a la teoría unitaria de la producción del espacio, por ejemplo: Neil Brenner ha puesto el énfasis a la representación del espacio y Edward Soja se ha interesado en los espacios de representación, sin embargo, sería importante relacionar las dimensiones faltantes para encuadrar la teoría unitaria de la producción del espacio, bajo esta última idea David Harvey se ha interesado en incorporar las tres dimensiones espaciales para explicar el dominio del capital en la producción del espacio. En el siguiente apartado exponemos con mayor detenimiento el tema.

\section{La influencia teórica de Henri Lefebvre en el diseño metodológico en David Harvey, Neil Brenner y Edward Soja}

Neil Brenner en su etapa como estudiante de la Universidad de Yale encontraría en David Harvey su primer soporte teórico en el análisis urbano, pero fue en la Universidad de Chicago que encontraría su principal marco teórico relacionando La production de l'espace y De l'État para proponer su conceptualización de la reorganización del espacio estatal en Alemania occidental (Sevilla, 2017, p. 43-46) y, que en años después marcarían la investigación de Brenner. Asimismo, el Estado como sustento de la representación del espacio ha sido un referente en la construcción teórica de Brenner, muestra de ello son las mutaciones del Estado durante el periodo fordista-keynesiano y su transición promovida por la reestructuración económica donde se observa el ascenso del neoliberalismo reorganizando la espacialidad Estatal (Brenner, 2017, p. 172-179).

Aunque, Edward Soja es uno de los máximos exponentes de la obra de Henri Lefebvre, tanto en los postulados teóricos y en las cuestiones empíricas que se expresan en la metrópolis de Los Ángeles. Esto se debe a la influencia que tuvo del libro La producción del espacio que daría el giro espacial como sustento teórico en Soja. Así pues, la tríada espacial es la que mayor resonancia ha tenido en él, ya que después revolucionaria su pensamiento espacial, en lo que ha llamado como: "la trialéctica de la espacialidad" (Soja, 2010, p. 187). La trialéctica 
de la espacialidad engloba tres momentos diferentes de la realidad. "El primer espacio (espacio percibido) se refiere al mundo experimentado directamente de los fenómenos cartografiables, y empíricamente mensurables" (Soja, 2010, p. 188). Mientras que "el segundo espacio (espacio concebido), por el contrario, es más subjetivo e 'imaginado', más preocupado por las imágenes y las representaciones de la espacialidad [...]" (Soja, 2010, p. 189). Sin embargo, al englobar al espacio percibido y concebido ha tenido como resultado la creación de un nuevo espacio, como él lo ha llamado: tercer espacio que comprende al espacio vivido de la interacción de la vida real que puede ser material y tangible, pero también de aquellos elementos que no pueden ser visibles y que corresponde a "la complejidad de la imaginación geográfica o espacial" (Soja, 2008, p. 40).

En lo concerniente a los momentos del método regresivo-progresivo, un estudio interesante donde se puede observar la aplicación del método bajo análisis lo realizaría Edward Soja para describir las transformaciones de la metrópoli industrial Los Ángeles por medio de imágenes satelitales, dicho ejercicio fue realizado en su escrito denominado "Los Ángeles desde el espacio: una visión desde mi ventana", publicado en Postmetrópolis: estudios críticos sobre las ciudades y las regiones (Soja, 2008), este mismo es una alusión a la paráfrasis del escrito de Lefebvre (2007, p. 22-27): Visto desde la ventana en su departamento en la ciudad de París para materializar el ritmo-análisis de la vida cotidiana de las calles parisinas.

Por último, David Harvey de alguna manera ha involucrado los postulados de Henri Lefebvre, sobre todo la teoría unitaria de la producción del espacio (Harvey, 1996, 2004), por mencionar algunos. Pero, uno de los primeros registros se daría en los albores de 1970 en el libro de Urbanismo y desigualdad social en donde Harvey (2007, p. 318) escribía lo siguiente: "[...] me siento mucho más seguro, acudiendo tanto a la obra de Lefebvre [...]" ya que "existe paralelismo entre sus criterios y los míos, y hay semejanzas en el contenido (lo que es alentador) y algunas diferencias en cuanto a énfasis e interpretación (lo que es sugestivo)". Mientras que, en 1990, recurría de nuevo en su libro Límites del capitalismo y teoría marxista al mencionar que: "Henri Lefebvre [...] ha sido el más persistente, por amplio margen, en su lucha por incorporar una dimensión espacial al pensamiento marxista" (Harvey, 1990, p. 340) ya que "[...] nos ha hecho notar repetidamente la importancia de la producción del espacio, la política del espacio y el papel del espacio en la reproducción social (principalmente en el contexto urbano)" (Harvey, 1990, p. 377).

De acuerdo con lo anterior, podemos señalar que el dominio del capital es un proceso en la producción del espacio urbano y que es sólo a partir de los principios que ha propuesto David Harvey que los podemos elucidar. Así pues, Harvey señala que el espacio urbano ha sido un medio importante de la dinámica del capital, es decir, un mecanismo sustancial en el proceso de acumulación (Harvey, 1990), como también es un receptor principal de los excedentes de producción y fuerza de trabajo (Harvey, 2007) y un promotor de estrategias para su reproducción y su correspondiente sobrevivencia. (Harvey, 2015) que a la par relaciona estrategias de carácter pro-empresarial (Harvey, 2014) y promociona espacios selectivos mediante el capital simbólico colectivo (Harvey, 2013). 


\section{Conclusiones}

No dudamos que el pensamiento de Lefebvre se condense el método dialéctico, es posible que lo dialéctico abone la configuración teórica y metodológica de las propuestas que hemos desarrollado en el presente escrito. A esto, la amplitud de la obra literaria de Henri Lefebvre ha promovido una vasta cantidad de interpretaciones en distintos campos disciplinarios y enfoques epistemológicos, por ello, Hess y Weigand (2006, p. 7) hacen referencia que Lefebvre es un "[...] autor de docenas y docenas de libros, H. Lefebvre no cerró su obra. Este permaneció abierto, sin terminar", aunque también la amplitud de métodos tiene esta misma virtualidad dejando la posibilidad del punto de partida de aplicación.

Los métodos bajo un sustento teórico abren distintos senderos de investigación e interpretación, a esto mismo, Lefebvre (1976g, p. 79) señalaría un punto central para estudiar la obra de Marx, él dice: "es un círculo vicioso. Se aprende el método estudiando la obra de Marx y para comprender la obra de Marx ya hay que comprender su método" en el pensamiento de Lefebvre para comprender sus métodos se condensa el factor histórico que responde al método regresivo-progresivo, segundo se sitúa su pensamiento tríadico y heterodoxo; tercero responde a la cuestión de la virtualidad que responde a la posibilidad de proponer caminos alternativos en constante movimiento contradictorio; y, cuarto es la capacidad de englobar totalidades abiertas para configurar diseños teórico-metodológicos.

\section{Referencias}

BRENNER, N. La "glocalización" como estrategia espacial estatal: el empresarialismo urbano y la nueva política de desarrollo desigual en Europa occidental. En: SEVILLA, A. (Ed.). Teoría urbana crítica y políticas de escala. Barcelona, ES: Icaria, 2017. p. 160-194.

ELDEN, S.; MORTON, A. D. Thinking past Henri Lefebvre: introducing "The theory of Ground Rent and Rural Sociology". Antipode, v. 48, n. 1, p. 57-66, 2015. doi: https://doi.org/10.1111/anti.12171

HARVEY, D. Diecisiete contradicciones y fin del capitalismo. San Cristóbal de Las Casas, MX: Universidad de la Tierra de Chiapas, 2015.

HARVEY, D. Espacios de capital. Tres Cantos, ES: Akal, 2014.

HARVEY, D. Ciudades rebeldes: del derecho a la ciudad a la revolución urbana. Tres Cantos, ES: Akal, 2013.

HARVEY, D. Urbanismo y desigualdad social. Madrid: Siglo Veintiuno, 2007.

HARVEY, D. La condición de la posmodernidad: investigación sobre los orígenes del cambio cultural. Buenos Aires: Amorrortu, 2004.

HARVEY, D. Justice, nature and the geography of difference. Cambridge, MA: Blackwell, 1996.

HARVEY, D. Límites del capitalismo y teoría marxista. Ciudad de México: Fondo de Cultura Económica, 1990. 
HESS, R. La méthode d'Henri Lefebvre. Revues Futur, 2004. Disponível em: http:// libertaire. free.fr/Analyselnstitutionnelle01.html. Acesso em: 18 fev. 2021.

HESS, R.; WEIGAND, G. Henri Lefebvre et son oeuvre. p. 1-14, 2006. Disponível em: http:// www.barbier-rd.nom.fr/H.\%20Lefebvre.pdf. Acesso em: 18 fev. 2021.

LEFEBVRE, $\mathrm{H}$. Hacia una arquitectura del placer. Madrid: Centro de Investigaciones Sociológicas, 2018.

LEFEBVRE, H. La producción del espacio. Madrid: Capitán Swing, 2013.

LEFEBVRE, H. El Estado moderno. Geopolítica(s) - Revista de Estudios sobre Espacio y

Poder, v. 3, n. 1, p. 137-149, 2012. doi: https://doi.org/10.5209/rev_GEOP2012.v3.n1.40288.

LEFEBVRE, H. La noción de totalidad en las ciencias sociales. Telos - Revista de Estudios

Interdisciplinarios en Ciencias Sociales, v. 13, n. 1, p. 105-124, 2011. Disponível em: https://www.redalyc.org/pdf/993/99318408008.pdf. Acesso em: 18 fev. 2021.

LEFEBVRE, H. Ritmo-análisis: espacio, tiempo y vida cotidiana. Nueva York: Continuum, 2007.

LEFEBVRE, H. La presencia y la ausencia: contribución a la teoría de las representaciones.

Ciudad de México: Fondo de Cultura Económica, 2006.

LEFEBVRE, H. La vida cotidiana en el mundo moderno. Madrid: Alianza, 1984.

LEFEBVRE, H. Lógica formal lógica dialéctica. Ciudad de México: Siglo Veintiuno, 1980.

LEFEBVRE, H. El derecho a la ciudad. Barcelona, ES: Península, 1978.

LEFEBVRE, H. De 1'Etat 3: le mode de production étatique. Paris: Union Génerate d'Éditions, 1977.

LEFEBVRE, H. De lo rural a lo urbano. Buenos Aires: Lotus Mare, 1976 a.

LEFEBVRE, H. De 1'Etat 2: théorie marxiste de l'Etat de Hegel á Mao. Paris: Union Génerate d'Éditions, $1976 \mathrm{~b}$.

LEFEBVRE, H. La revolución urbana. Madrid: Alianza, 1976c.

LEFEBVRE, H. Más allá del estructuralismo. Buenos Aires: La Pléyade, 1976d.

LEFEBVRE, H. Espacio y política: el derecho a la ciudad II. Barcelona, ES: Península, $1976 \mathrm{e}$.

LEFEBVRE, H. Tiempos equívocos. Barcelona, ES: Kairós, $1976 f$.

LEFEBVRE, H. Síntesis del pensamiento de Marx. Barcelona, ES: Nova Terra, 1976g.

LEFEBVRE, H. Hegel, Marx, Nietzsche (o el reino de las sombras). Ciudad de México: Siglo Veintiuno, 1976h.

LEFEBVRE, H. Manifiesto diferencialista. Ciudad de México: Siglo Veintiuno, 1975.

LEFEBVRE, H. La revolución de hoy. Ciudad de México: Extemporáneos, 1974a.

LEFEBVRE, H. E1 materialismo dialéctico. Buenos Aires: La Pléyade, 1974b.

LEFEBVRE, H. Estructuralismo y política. Buenos Aires: La Pléyade, 1973a. 
LEFEBVRE, H. La violencia y el fin de la historia. Buenos Aires: Siglo Veinte, 1973b.

LEFEBVRE, H. El marxismo. Buenos Aires: Eudeba, 1973c.

LEFEBVRE, H. Contra los tecnócratas. Buenos Aires: Granica, 1972.

LEFEBVRE, H. Introducción a la modernidad. Madrid: Tecnos, 1971.

LEFEBVRE, H. Lenguaje y sociedad. Buenos Aires: Proteo, 1967.

LEFEBVRE, H. Problemas actuales del marxismo. Córdoba, AR: Nagelkop, 1965.

LEFEBVRE, H.; GUTERMAN, N. Que es la dialéctica. Buenos Aires: Dédalo, 1964.

LENCIONI, S. Totalidad y tríadas: comprendiendo el pensamiento de Lefebvre. En: MATTOS, C.; LINK, F. (Eds.). Lefebvre revisitado: capitalismo, vida cotidiana y el derecho a la ciudad. Santiago: RIL, 2015.

MARTINS, J. S. A dialética do método regressivo-progressivo em dois temas brasileiros: cidade e campo. In: REUNIÃO ANUAL DA ANPOCS - VINTE ANOS SEM HENRI LEFEBVRE, 35., 2011, Caxambu. Anais... Caxambu, MG, 2011. Disponível em: https://www.anpocs.com/index.php/encontros/papers/35-encontro-anual-daanpocs/mr-5/mrl7/1279-a-dialetica-do-metodo-regressivo-progressivo-em-dois-temasbrasileiros-cidade-e-campo/file. Acesso em: 18 fev. 2021.

MARTINS, J. S. As temporalidades da história na dialética de Lefebvre. En: MARTINS, J. S.

(Org.). Henri Lefebvre e o retorno à dialética. São Paulo: Hucitec, 1996.

SCHMID, C. Henri Lefebvre's theory of the production of space: toward a three-dimensional dialectic. En: GOODNEWARDENA, K.; KIPFER, S.; MILGROM, R.; SCHMID, C. (Ed.). Space, difference, everyday life: reading Henri Lefebvre. New York/ London: Routledge, 2008. p. 27-45.

SEVILLA, A. Nuevos horizontes: hacia una investigación de la urbanización planetaria. En: SEVILLA, A. (Ed.). Teoría urbana crítica y políticas de escala. Barcelona, ES: Icaria, 2017.

SOJA, E. Tercer espacio: extendiendo el alcance de la imaginación geográfica. En: BENACH, N.; ALBET, A. (Org.). Edward W. Soja: la perspectiva postmoderna de un geógrafo radical. Barcelona, ES: Icaria, 2010. p. 181-209.

SOJA, E. Postmetrópolis: estudios críticos sobre las ciudades y las regiones. Madrid: Traficantes de Sueños, 2008.

STANEK, L. J. Henri Lefebvre and the concrete research of space: urban theory, empirical studies, architecture practice. Doctoral Thesis (Empirical Studies, Architecture Practice Proefschrift) - Faculty of Architecture and the Built Environment, Delft University of Technology, Delft, NL, 2008.

STANEK, L.; SCHMID, C. Teoría, no método: Henri Lefebvre, investigación y diseño urbanos en la actualidad. Urban, n. 2, p. 59-66, 2011. Disponível em: http://polired.upm.es/ index.php/urban/article/view/1491. Acesso em: 18 fev. 2021. 
THEODORE, N.; PECK, J.; BRENNER, N. Urbanismo neoliberal: la ciudad y el imperio de los mercados. Temas sociales, Santiago de Chile: Ediciones Sur, v. 66, p. 1-11, 2009. Disponível em: http://www.sitiosur.cl/detalle-de-la-publicacion/?PID=3532. Acesso em: 18 fev.2021.

Recebido em: 29 jan. 2020

Aprovado em: 5 fev. 2021 